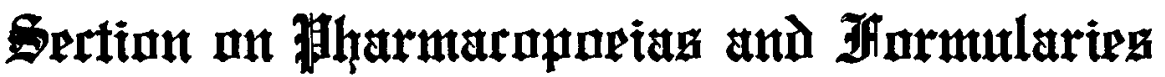

\author{
Papers Presented at the Sixty-Second Annual Convention
}

\section{THE HOMEOPATHIC PHARMACOPCELA OF THE UNITED STATES.}

GEORGE M. BERINGER, PH. M.

The appearance of the Third Edition of the Homeopathic Pharmacopoia of the United States, is one of the events of the present year that has received very little consideration in pharmaceutical circles. Homeopathic medicines are dispensed by many pharmacists and, in some localities, to quite a large extent. A knowledge of the basic principles of homeopathic pharmacy and the differences in the methods and practices should be acquired by every pharmacist. A more extended acquaintance with the materia medica of homeopathy is essential to those regularly dispensing such medicines and for these a careful study of the book is necessary. It has been the desire of the homeopathic school of medicine to have the Food and Drugs Act of June 30,1906, amended so as to recognize this volume as the legal authority and standard for homeopathic drugs. These various considerations all indicate that homeopathic standards are of interest and importance to the drug trade and justify the presentation of this paper.

At the meeting of the American Institute of Homeopathy held in Pittsburgh in 1912, a committee of six homeopathic physicians was appointed to prepare a revision of the Homeopathic Pharmacopoeia, the previous edition of which had been published about eleven years prior. The following year, the committee reported the completion of the revision and the publication was authorized and the book has now appeared within about two years after the appointment of the committee.

The promptness with which this committee has completed its work, is certainly very commendable. The impression, however, must not be conveyed that the revision has been made with that thoroughness and aim at scientific exactness that has characterized the revision of the Pharmacopœia of the United States.

A critical examination of the volume shows that but very few pages of the previous revision have been rewritten. The third edition contains 680 pages, the second edition had 674 ; the additional six pages are accounted for by the introduction of a new table "Showing Percentage of Alcoholic Strength of Tinctures."

The revision has been largely one of bookmaking with the rewriting reduced to a minimum. The preface, historical and introductory notices occupy twenty pages as in the previous edition. The General Pharmacy, containing instructions for making tinctures, dilutions and standards for solvents and diluents, occupies the same space and page for page as in the former edition and with only a few minor changes. Part II is devoted to "Special Pharmaceutics," or the official 
homeopathic materia medica and, as in the previous edition, this occupies pages 51 to 596 , inclusive.

The admissions have been artfully fitted into the text. Where it became necessary to introduce a new drug the plan commonly adopted was to select a drug for deletion and the page plate cut in such a way as to make the changes necessary with the least amount of type setting. Thus on page 482, Ranunculus Flammula was deleted and Radium Bromide sandwiched in with two other Ranunculi before and two following and thus the strictly alphabetical arrangement was destroyed. On page 532, Spiræa Ulmaria, queen of the meadow, was deleted and Sparteine Sulphate was introduced, following Spigelia and not in alphabetical sequence. As the text for Sparteine Sulphate occupied less space than that previously required for Spiræa, several pages had to be recast, but the printer has minimized the resetting by leaving a blank space for about one-fourth of page 532. These examples serve to show an easy method of pharmacopœial revision.

Ten admissions to the official materia medica are recognized. These additions include a number of medicines more or less used in both schools, such as hawthorn berries, echinacea, white ash bark, thyroid gland, sparteine sulphate, strychnine phosphate and radium bromide. Not the least to be noted as an admission is Mephitis Mephitica, Skunk Poison, the offensive fluid secreted by the anal glands of the polecat.

The deletions are Coriaria ruscifolia, the toot berry of New Zealand, the strawberry, mercurous acetate, mercury black sulphide replaced by the red mercuric sulphide, ranunculus flammula, spiræa ulmaria, strychnine alkaloid and linden flowers still extensively used, especially among the Italians.

The volume reasserts that the essentials of homeopathic pharmacy, are the simplicity or singleness of its preparations and cleanliness. The drugs are never mixed or compounded in their preparation or in their dispensing. In accordance with the homeopathic axiom, only one medicine is used at a time. Each drug in its natural state, after proper comminution, is added to a prescribed solvent for the purposes of extracting and preserving and as a means of dilution. Great stress is laid upon the importance of cleanliness and the most conscientious care in the handling of drugs of different kinds so as to protect them from the vapors, odors and dust of others and storage is to be in cool, airy and darkened places.

Drugs are defined "as substances which have the power of disturbing the health of the living organism." The Homeopathic materia medica is in the main derived from the vegetable kingdom; the plant drugs constitute the majority of the official medicines. Thirty-two of the drugs included are of animal origin of which we are informed "only a few are in common use." The mineral kingdom is the source of many and also some of the chemical constituents of plants as well as some artificial chemical products are included.

The dry crude drug remains "the unit of medicinal strength." The directions of the British Homeopathic Pharmacopœia regarding this is adopted. This reads: "In every instance, the dry crude substance is to be taken as the starting point from whence to calculate its strength, and the mother tinctures contain all the soluble matter of one grain of the dry plant in ten minims of the tincture." 
In the preparation of tinctures from fresh plant drugs, the amount of moisture present is determined by drying a weighed portion on a water-bath until it ceases to lose weight. Allowance for the percentage of water so determined, is to be made in the preparation of the menstruum. For the extraction of drugs either maceration or percolation is permissible. The former process is "recommended for gummy, mucilaginous substances and those plant drugs having much viscid juice."

It is to be observed that the mother tinctures thus made correspond to the first recimal dilutions $(1 \mathrm{x})$. The decimal system of dilution, that is one part of the drug or tincture to nine of diluent, is adopted as the standard and scale of attenuation and notation; so each successive dilution or trituration contains onetenth as much of the dry substance as the preceding dilution or trituration. The older method of dilution recommended by Hahnemann and adopted for many years by his followers, was the centesimal scale, where each attenuation contained $1 / 100$ part as much of the drug substance as the preceding attenuation. The decimal scale "affords less opportunity for the loss of curative opportunities or 'chances' than the other."

The solvents and diluents employed in homeopathic pharmacy are few and are tersely treated in "Part I. Gencral Pharmacy." The descriptions, properties and" tests are not stated with that positive exactness that is observed in other modern pharmacopœias, and the critic will note their insufficiency. Distilled water has no test for limit of ammonia or nitrous oxide. No ash limit is fixed for sugar of milk. Half of an ounce of a hot saturated solution (aqueous) ? of milk-sugar is directed to be added to an equal quantity: of sodium hydrate to saturation, in order to show the inverting power of alkalies on lactose and subsequent reduction of copper solutions. A few cubic centimeters will be all that a chemist would require to make such tests. Under tests for alcohol it is stated "that when one volume of alcohol is mixed with half its volume of test-solution of potassium hydrate, the liculud should not at once become dark-colored; the non-appearance of the dark color will prove the absence of aldehyde, methyl alcohol or tannin." No other test is given and this certainly could not alone be accepted as a discriminating test for the presence or absence of methyl alcohol.

The directions regarding prescriptions are short and commendable. It is stated that the writing of prescriptions falls exclusively within the duties of the physician; he should exercise the greatest care and exactitude in giving his instructions to the pharmacist who is to be governed by them: not the slightest doubt should exist concerning the physician's directions: the name is to bc plainly written, preferably, in Latin; the form should next be stated, that is tincture. dilution, trituration; the dosage form and number of doses should be explicitly given; and the dose and frequency of repetition should be plainly written under the head of "Signa." "Abbreviations facilitate the writing of prescriptions, they do not add to their intelligibility and hence should only be used in strict obedience to rules of abbreviations."

The presentation of the monographs in Part II follows the following general form:- Official title in Latin, Official English title, natural order, if of animal or vegetable origin; Synonyms, Latin, English and Foreign; Description; Habitat; History; Part Used ; Preparations. 
In those drugs that are considered as very active poisons, "requiring special caution on the part of physician and pharmacist," there is introduced in the paragraph "description," a maximum dose statement. Thus in Acidum Carbolicum, "A poison, maximum dose 2 grains highly" diluted with water." Under Acidum Hydrocyanicum, "An active poison, maximum dose of 2 per cent. solution, 10 Minims." Under Arsenicum Album, "An active poison, maximum dose 1/12 grain, not to exceed $1 / 6$ grain per day."

As by far the larger percentage of homeopathic materia medica is of vegetable origin, one would reasonably expect to note in this revision a decided improvement in the botany and pharmacognosy. In this we are sorely disappointed as only a few unimportant changes have, here and there, been made. From the studies of botanists and pharmacognocists for many generations, there has accumulated a mass of facts regarding the limitations of botanical familics, genera and species; the botanical synonomy; the correction of names and errors of earlier botanists who frequently worked with insufficient materials; the sources of drug and food materials; the structural and anatomical characteristics of plants and drugs, etc. Little, if any, reference seems to have been made by the revisers to this storehouse of available knowledge, and even the work of systematic botanists on our native flora appears to have been neglected, as well as that on the foreign.

The Latin title given to a drug of vegetable origin is commonly the botanical binomial of the plant. As a rule, such titles arc.quite appropriate, but for others their validity is questionable. As examples, Guaiacum Officinale with the synonyms Lignum guaiaci. Lignum zitc, Bois de gayac and Guaiaholz for Guaiac Resin, and Croton Tiglium. for Croton Oil, which could readily have been placed with the other oils, such as cod liver and castor oils and oils of cajaput and sandal wood.

The determination to adhere closely to the rule to retain as the Latin title the name under which the drug was introduced into homeopathic literature, has led to the continuation of a number of names that should long since have been discarded. Some of these perpetuate old errors and of others it would be quite difficult to trace their history or connection with the drug. The "mephitic and alliaceous" skunk cabbage is a characteristic illustration. The title given is Pothos Fœtidus. Presumably this goes back to the Pothos fœtid $a$ of Michaux; but it was early recognized that this plant was very distinct and Nuttall and other botanical contemporaries of a century ago pointed out that this plant could not be classified with the tropical American plants of the genus Pothos, nor with Linncus Dracontium, and so Nuttall classified it under Salisbury's genus Symplocarpus and Symplocarpus fortidus is the name that was commonly used by botanists for a century. It is now known that Rafinesque had even prior to Nuttall ascribed this plant to a properly described genus Spathyema, a name that is very appropriate and has bcen accepted by Britton and Brown and the more recent systematists as the correct name in accordance with the rules for botanical nomenclature. Yet the correct name, Spathyema fotida Raf., is not given even as a synonym.

The subject of Synonyms is admittedly a difficult problem and should be given 
consideration in a pharmacopoia primarily for the purpose of determining standards, for defining exactly to what drugs the names are to be properly applied. The treatment here is such as to perpetuate many errors that scientists have long since corrected or buried and to create innumerable questions and doubts as to standards and what it is intended to include under many of the official titles. The revision has done absolutely nothing toward clarifying this confusion and jumble of the former editions.

Under the title of "Synonyms," numerous binomials are given, but in no instance is the authority for the name given. Any one who has paid the least attention to systematic botany, knows how dangerous is such a practice. The same name has not unf requently been employed by one botanist as well as by different botanists to plants that were later differently classified and properly named. To continue to perpetuate such erroneous and misleading synonyms in a work on drug standards that seeks recognition as a legal authority, is inexplicable.

The few examples of this treatment of botanical synonomy permitted by space, will suffice to exhibit what I consider the grave defect common throughout part II. Under Aloe Socotrina are given as synonyms names that are with proper authority considered the sources of East Indian, Barbadoes and Cape Aloes.

Belladonna has twelve binomials given as Latin synonyms: two place it in genus atropa, two in the genus belladonna and eight different solanums would include it in that genus.

Chamomilla with nine Latin synonyms with six genera named, with Matricaria Chamomilla Linne, which alone would have definitely fixed a standard, given next to the last.

Cimicifuga has nine English synonyms in addition to twelve Latin which classify it with the following genera: Cimicifuga, Actæa, Botrophis, Christopheriana and Macrotys.

Cina (Santonica) has eighteen Latin synonyms, twelve of which are binomials and would recognize four species of absinthium and eight of artemisia. There is certainly need for a more definite statement here as some of the species of artemisia named contain no santonin and others very little.

Cinchona Officinalis, or China with Peruvian Bark as an English synonym. The Latin synonyms given are mostly those of plants that many years ago were considered as possible sources of commercial varieties of cinchona. The change in source due to the extensive cultivation receives scant consideration. C. succirubra is named in the text though not included in the synonyms, but $C$. Ledgeriana, Molus, is not mentioned at all. It was to the study of the effects of Cinchona that Hahnemann attributed his discovery of the "law of cure."

Cistus Canadensis-Frostweed. Here one notes a veritable confusion. The genus is Helianthemum and not Cistus as given in the title. The synonyms given include Lechea major, which title is properly applied to our common pin weed Lechea major Mich., an entirely different plant.

Digitalis Purpurea-Campanula sylvestris is the first stated synonym. Is it not time that such an error as the naming of a scrophulariaceous plant of the genus Digitalis as belonging to the Campanulas should be forgotten? 
Hyoscyamus Niger-The synonyms given include $\mathrm{H}$. agrestis and $\mathrm{H}$. flavus, two of the European species that have been noted as sophistications occasionally collected and admixed with the official hyoscyamus.

Illicium Anisatum-Star Anise. In this monograph, nine binomials are given, yet the uncertainty of the source is evidenced in the statement under History carried over from the previous revision, "although having many synonyms it is doubtful if star anise is the product of all." The intent is doubtless to describe the innocuous drug star anise, but both in the title (Illicium Anisatum) and among the synonyms (Illicium religiosum) is the poisonous star anise designated. The revisers were probably not aware of the study made in 1888 by J. D. Hooker, who determined that the true star anise was obtained from a species he named Illicium verum and that I. anisatum Linnæus and I. religiosum Siebold were different names for the plant yielding a false and poisonous substitute for the true drug.

Scilla Maritima-Squill. The binomials given would classify this plant as coming from the following genera: Cepa, Ornithogalum, Pancratium, Sancratium, Scilla, Squilla, and Urginea.

It is difficult to understand how with such misleading synonomy that purity and singleness of the drugs that it is claimed as so essential to homeopathic pharmacy, can be assured.

The animal drugs include quite a variety, some few of which are common to both schools. Among these may be mentioned Animal Charcoal, Cantharides, Castor (formerly official in the U. S. P., 1870), Cochineal, Musk and Cod Liver Oil. The Honey Bee supplies two titles, that of the Apis Mellifica or Honey Bee with directions for making a tincture from the live bees, and the Apis Virus, being the Honey Bee Poison, with formula for making a trituration from the extracted stings. The Star Fish, Red Coral, Fresh Water Sponge, the juice of the Purple Mollusk and Sepia, the dried inky secretion of the Cuttle Fish, are some of the oddities in this group of drugs.

Among snake poisons are given Crotalus, the Rattlesnake venom, the use of which hypodermatically as a cure for epilepsy has been recently exploited in general practice; Elaps Corallinus, coral snake; Lachesis or Viper; and the Naja Cobra venoms.

From the Spiders we have Aranea or Diadem Spider, Mygale or Bird Spider, the Tarantula, of which two distinct titles and species are named, the Spanish and Cuban, and the Theridion or Black Spider of Curacoa.

In the treatment of chemicals, one notes that the tendency has been to follow what has been called the "bob-tail" spelling, that is, using the termination "id" for Chlorides and Bromides, and "fate" for Sulphates. Yet even here there is a lack of consistency. Radium Bromide is found with the "ide" termination, and Sparteine Sulphate is with the "phate" termination. Yet Cinchonine Sulphate is Cinchonin Sulfate. In some of the alkaloids, the U. S. P. rule of terminating alkaloidal names in "ine" has been followed. In others, it has been forgotten. For examples, Cinchonin Sulfate, Eserin, Bebeerin, Apomorphin Hydrochlorid, Pilocarpin Hydrochlorid. Others are spelled with the "ine," such as Codeine, Hydrastine, Morphine, Narceine, Narcotine, Caffeine, Brucine, Atropine, Atropine 
Sulfate. In some of the Quinine salts, the Quinine is spelled with "in," the others with "ine" terminations, and for some reason Santonin has been changed to Santonine.

Some of the Latin titles given for chemicals and mineral products are simply the English without any attempt at latinizing. For example, Borax and Petroleum.

Throughout the chemical monographs the molecular weights have been corrected on the basis of the recent international atomic weights, but through some oversight there is left in the book (page 606), the old table of atomic weights based on $\mathrm{H}=1$ and $\mathrm{O}=15.96$, and so we have here again a dual standard for atomic weights and calculations of molecular weights.

There is no attempt at assaying any of these chemicals. In the descriptions the strength of standard is sometimes mentioned, but these descriptions are not always of the medicinal article. Acid Hydrocyanic is accompanied with a description describing an acid which boils at $27^{\circ}$ and congeals at $15^{\circ}$. Here the attempt is evidently made to describe the pure Hydrocyanic Acid, yet it is subsequently stated that $2 \%$ acid is to be used in making the dilutions and the dose given is for the $2 \%$ acid.

Throughout the chemicals the United States Pharmacopoia standard is frequently referred to, sometimes properly and sometimes without recognizing the changes that have taken place in the more recent editions of the U. S. P. Under the title of Ferrum Carbonicum, Saccharated Carbonate of Iron, the process of the U. S. P. VIII is designated. Under the title of Ferrum Iodatum, the synonym of Saccharated Iodide of Iron, a formula is attached credited to the U. S. P. without date. The formula for that preparation, however, is that which was included in U: S. P., 1890. Under the title of Ferrum Muriaticum, there is given a formula for the preparation of Solution of Ferric chloride, U. S. P., but here the formula of the U. S. P., 1890, is retained without noticing that the U. S. P. VIII (1900) reduced the Iron content of this solution from $37.8 \%$ Ferric Chloride to $29 \%$.

It is to be noted that throughout the book, formulas are only given for the preparation of Tinctures and Triturations with their dilutions and attenuations. No mention is made of other forms of medications that are used in homeopathic pharmacy, such as liniments and ointments and for which standard formulas should be included in a pharmacopocia.

Part 3 of the book is devoted to select tables for reference. The first of these is the list of signs and abbreviations used in prescription writing. Another useful table is that of the list of medicines with the pronunciation of the titles correctly indicated.

\section{SENSITIVE TEST FOR IRON.}

A little hydrazine is added in order to reduce ferric to ferrous iron, or to prevent oxidation of ferrous salt. To $50-70$ mils of the solution a little saturated alcoholic dioxime solution is added. If the smallest traces of iron are present the liquid becomes intensely red.-L. Tschugaeff and B. Orelkin (Zscht. Anorg. Chem., 1914). 